\title{
Anesthetic Effects of Varying Doses of Fentanyl Combined With Spinal Bupivacaine in Caesarean Delivery
}

\author{
Puja Thapa', Amir Babu Shrestha² and Mallika Rayamajhi ${ }^{1}$
}

${ }^{1}$ Department of Anesthesiology, Nepalese Army Institute of Health Sciences, Shree Birendra Hospital, Chhauni, Kathmandu, Nepal

2Paropakar Maternity Hospital, Thapathali, Kathmandu, Nepal

\section{ABSTRACT}

Introduction: Spinal opioids have gained popularity in recent years as they augment the analgesia produced by local anesthetics. Fentanyl is one of the opioids used for such purpose however the optimal dose has not been described adequately in the literature available so far in our setup. The aim of this study is to find out the effect of adding various doses of Fentanyl to low dose hyperbaric Bupivacaine intrathecally.

Methods: 75 parturients scheduled for caesarean delivery were randomly allocated into three groups (Bupivacaine-Fentanyl) BF10, BF20 and BF30 who received intrathecal 0.5\% hyperbaric Bupivacaine $1.6 \mathrm{ml}$ with Fentanyl $10 \mu \mathrm{g}, 20 \mu \mathrm{g}$ and $30 \mu \mathrm{g}$ respectively. Total volume was made to $2.2 \mathrm{ml}$ by adding normal saline. The outcomes measured were peak sensory level, degree of motor block, quality of intraoperative anesthesia, duration of effective analgesia, neonatal APGAR score and side effects were noted if any.

Results: Peak sensory level and degree of motor block was similar in all the groups. Peak sensory level (Thoracic Dermatome) was $4.52 \pm 0.82,4.32 \pm 0.62$ and $4.32 \pm 0.74(\mathrm{p}=0.540)$ in BF10, BF20 and BF30 respectively. Degree of motor block was not significantly different $(p=1.000)$. Quality of intraoperative anesthesia improved from BF10 to BF20 $(\mathrm{p}=0.040)$ but did not improve significantly from BF20 and BF30 $(p=0.189)$. Duration of effective analgesia prolonged as the dose of Fentanyl increased which was in minutes $173.64 \pm 41,216.80 \pm 32$ and $273.16 \pm 35(\mathrm{p}=0.000)$ in BF10, BF20 and BF30 respectively. Neonatal APGAR scores were similar in all groups and very little adverse effects in higher doses.

Conclusions: The combination of $1.6 \mathrm{ml}$ of $0.5 \%$ hyperbaric Bupivacaine and $20 \mu \mathrm{g}$ of Fentanyl intrathecally provides excellent surgical anesthesia, prolonged postoperative effective analgesia with very few side effects. Increasing the dose of Fentanyl beyond it could prolong the postoperative pain relief but at the cost of increased adverse effects.

Keywords: Bupivacaine; Caesarean delivery; Fentanyl; Intrathecal

Correspondence: Puja Thapa, Department of Anesthesiology, Nepalese Army Institute of Health Sciences, Shree Birendra Hospital, Chhauni, Kathmandu, Nepal.Email: thapa_puza@yahoo.com

DOI: $\underline{\text { http://dx.doi.org/10.3126/mjsbh.v17i1.18614 }}$

Submitted on: $2017-11-15$

Accepted on: 2018-01-07 


\section{INTRODUCTION}

A caesarean section (C-section) is a form of childbirth in which a surgical incision is made through a mother's abdomen (laparotomy) and uterus (hysterotomy) to deliver one or more babies. Today, caesarean delivery is being increasingly performed for various indications. As per the recent statistics from 150 countries, currently $18.6 \%$ of all births occur by $\mathrm{C}$-Section, ranging from $6 \%$ to $27.2 \%$ in the least and most developed regions, respectively. Latin America and the Caribbean region has the highest $\mathrm{C}$-Section rates of $(40.5 \%)$ and Asia has rate of (19.2\%). ${ }^{1}$ Different forms of anesthetic techniques have been utilized for caesarean delivery. Spinal anesthesia offers the advantages of simplicity, rapid onset, and dense neural blockade. It is associated with negligible maternal risk of systemic local anesthetic toxicity, minimal transfer of drug to the infant, and negligible risk of local anesthetic depression of the infant. Generally 12 to $15 \mathrm{mg}$ of intrathecal hyperbaric Bupivacaine is used for caesarean section. ${ }^{2}$ With higher doses of hyperbaric Bupivacaine, incidence of intraoperative visceral pain associated with higher blocks is reduced. ${ }^{3}$ However, the use of this dose range has been associated with an incidence of maternal hypotension.

Addition of intrathecal Fentanyl to hyperbaric Bupivacaine markedly prolongs the duration of sensory blockade and enhances the quality of intraoperative analgesia as compared to hyperbaric Bupivacaine alone. Fentanyl is associated with minimal side effects as compared to other opioids (morphine and pethidine) when used for spinal anesthesia for caesarean section. However, there are very scarce literatures regarding the optimal dose of Fentanyl to be used with the least possible adverse effects.

This study aims to monitor the effect of different doses of intrathecal Fentanyl combined with
Bupivacaine on improving the quality of spinal block and avoiding the complications of higher doses of local anesthetics in parturients.

\section{METHODS}

It was a hospital based prospective, randomized, double-blind interventional study carried out in a tertiary maternal care center from February to April 2013 after obtaining approval from the Institutional Review Board and Research Committee. It was calculated that 25 patients in each group would be required to have $95 \%$ confidence interval and power of $90 \%$ in the study .

After obtaining informed written consent, the parturients undergoing caesarean section meeting the inclusion criteria were randomized. Exclusion criteria were patient refusal, allergy to the study drugs, local infection at the site of puncture, coagulopathy, intracranial hypertension, PIH, cardiac diseases, failure of the procedure, fetal distress, fetal maturity less than 36 weeks.

They were randomly allocated into three groups identified as BF10, BF20 and BF30; each group received intrathecal $0.5 \%$ hyperbaric bupivacaine $1.6 \mathrm{ml}$ with fentanyl $10 \mu \mathrm{g}, 20 \mu \mathrm{g}$ and $30 \mu \mathrm{g}$ respectively. Total volume was made $2.2 \mathrm{ml}$ by adding normal saline as needed. Standard monitoring included pulse oximetry, non-invasive blood pressure (NIBP) and electrocardiography (ECG). The parameters taken into consideration were peak sensory level, degree of motor block, quality of intraoperative anesthesia, duration of effective analgesia, neonatal APGAR score and side effects if any.

The peak sensory level was defined as the highest level of loss of sharp sensation by using a pinprick test which is recorded bilaterally at the mid clavicular line at 2, 5, 10, 15, 20, 25 and 30 minutes after intrathecal injection. The quality of intraoperative analgesia was evaluated by the patient at 
Table 1. Peak sensory level among different groups

\begin{tabular}{|l|l|l|l|l|r|r|}
\hline \multicolumn{3}{|c|}{$\begin{array}{c}\text { Peak sensory level (Dermatome) } \\
\text { with mean } \pm \text { SD }\end{array}$} & \multicolumn{5}{c|}{ p value } \\
\hline BF 10 & BF 20 & BF 30 & $\begin{array}{c}\text { Among 3 } \\
\text { groups }\end{array}$ & BF 10 to BF 20 & BF 20 to BF 30 & BF 30 \& BF 10 \\
\hline $4.52 \pm 0.82$ & $4.32 \pm 0.62$ & $4.32 \pm 0.74$ & 0.54 & 0.657 & 0.09 & 0.27 \\
\hline
\end{tabular}

Table 2. Duration of effective analgesia amongst various study groups in minutes

\begin{tabular}{|c|c|c|c|c|c|c|}
\hline BF10 & BF20 & \multicolumn{2}{|c|}{ BF30 } & \multicolumn{4}{|c|}{ p value } \\
\hline & & & $\begin{array}{c}\text { Among 3 } \\
\text { groups }\end{array}$ & BF10 \& BF20 & $\begin{array}{c}\text { BF20 \& } \\
\text { BF30 }\end{array}$ & $\begin{array}{c}\text { BF30 \& } \\
\text { BF10 }\end{array}$ \\
\hline $173.64 \pm 41$ & $216.80 \pm 32$ & $273.16 \pm 35$ & 0.000 & 0.000 & 0.000 & 0.000 \\
\hline
\end{tabular}

15 minute intervals using 4-point scale as excellent, adequate, inadequate and major discomfort. 4 Degree of motor block was assessed bilaterally using a 4-point Bromage scale as 0, 1, 2, 3.5 in 5, 10 and 15 minutes. Duration of effective analgesia was taken from the time of intrathecal injection till the demand of first rescue analgesic dose and was assessed by using a visual analogue scale. The occurrence of adverse events like hypotension, bradycardia (heart rate $<60$ beats/minute), shivering, pruritus, urinary retention, nausea and vomiting, dizziness, sedation, respiratory depression or any other side effects were monitored for till 24 hours postoperatively. Neonatal APGAR scores at one and five minutes of birth was assessed.

Collected data was analyzed by means of statistical software SPSS 20.0. Chi-square and Fisher's Exact test were used to see the association between groups for categorical variables. Student's t-test and ANOVA was applied to see significant differences between the groups for continuous variables. The pvalue less than 0.05 was taken as significant.

\section{RESULTS}

Total 75 parturients were enrolled for the study, whose mean age was $24.40 \pm 4.6,25.20 \pm 5.2$ and $24.96 \pm 5.3$ years in BF10, BF20 and BF30 group respectively. There was no significant variation in weight and height. The mean duration of surgery in $\mathrm{BF} 10, \mathrm{BF} 20$ and BF30 were $55.68 \pm 11.8,52.12 \pm$ 7.3 and $50.92 \pm 7.6$ minutes respectively. The ASA physical status of the patients was comparable in all groups. In group BF10 and BF20 all patients were ASA I whereas in group BF30, 21 patients were ASA I and four were ASA II. There was no significant difference in heart rates and blood pressure between the groups at any time after subarachnoid block. There was no statistical difference in peak sensory level between all the groups $(\mathrm{p}=0.54)$, which is shown in detail in Table 1.

Quality of intraoperative analgesia improved with the increasing dose of Fentanyl from $10 \mu \mathrm{g}$ to $30 \mu \mathrm{g}$. Other additional analgesics or general anesthesia is not required for any. Statistically significant difference $(p=0.00)$ was found between all three groups ( Figure 1).

Intensity of motor block was also similar in all three groups. Most of the patients had Bromage scale of 2 in all groups as shown in Figure 2. Duration of effective analgesia, defined as time to demand of first rescue analgesic, was longest in $30 \mu \mathrm{g}$ and shortest in $10 \mu \mathrm{g}$. Duration of effective analgesia increased with increasing dose of intrathecal 


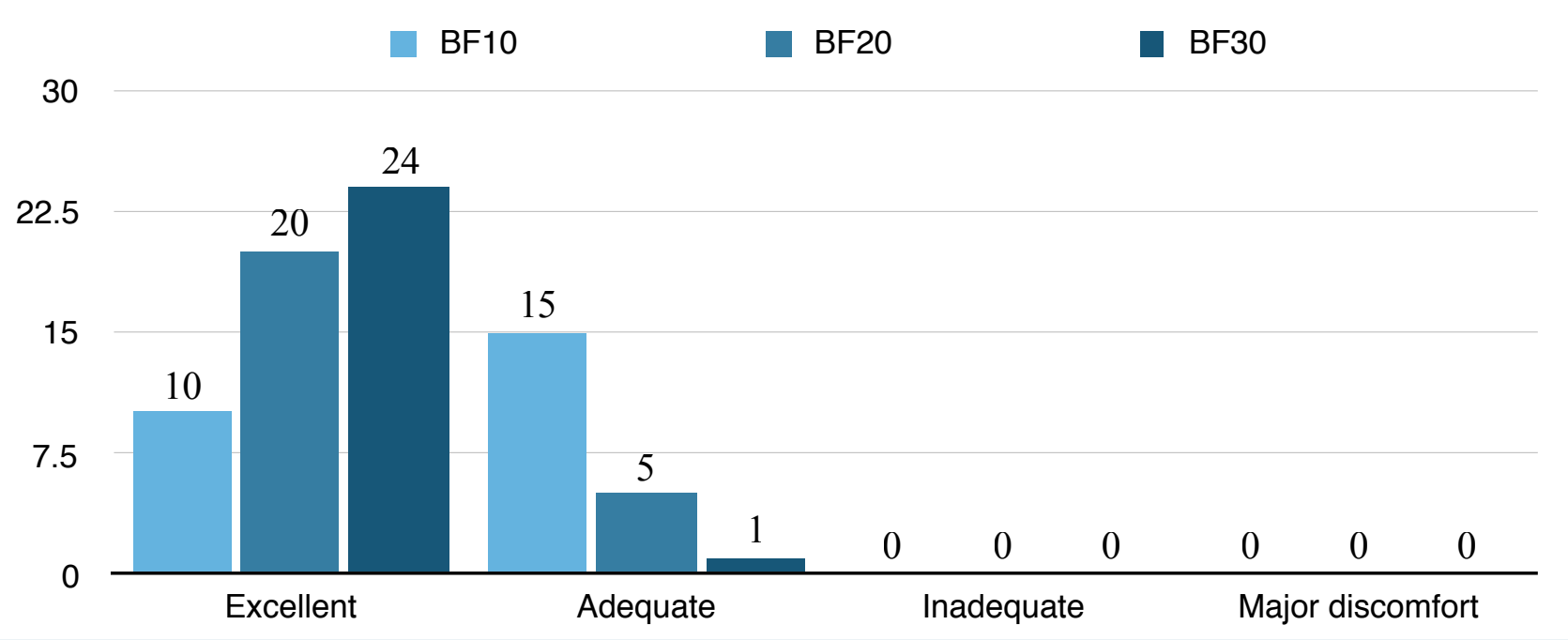

Figure 1. Quality of intra-operative analgesia amongst the various study groups

Fentanyl. The test was statistically significant $(p=0.000)$ ( Table 2).

Neonatal condition was similar in all groups with APGAR scores almost always above 7 at one minutes and five minutes. In all babies of Group BF10 and BF20, APGAR score was $\geq 7$ in 1 and 5 minutes. Whereas in Group BF30, one baby had score of $<7$ at 1 minute but had $\geq 7$ at 5 minutes. APGAR score was not significantly different between the groups.

Two cases of BF10 and one case of BF30 group had hypotension and both where managed with intravenous fluids and Mephentermine. Four patients from BF30 group and one patient from BF20 group developed pruritus of which all patients received intravenous Ondansetrone. Other side effects like bradycardia, shivering, urinary retention, nausea / vomiting, dizziness were not observed. Sedation score was assessed after 30 minutes of intrathecal injection of study drug. Scores were among 1 and 2. Overall, there was no statistical difference in sedation score between the groups during intra-operative period $(\mathrm{p}=0.948)$.

\section{DISCUSSION}

In our study, all groups received fixed intrathecal dose of Bupivacaine combined with different doses of Fentanyl which is 10,20 and $30 \mu \mathrm{g}$. This study was performed to select the best possible combination of dose of Fentanyl and Bupivacaine used in spinal anesthesia in caesarean section to avoid the complications of higher doses of local anesthetics and give better patient satisfaction. Peak level of sensory analgesia was similar in all three groups. It shows that level of sensory level depends upon the dose of Bupivacaine and is not influenced by doses of Fentanyl if volume of drug is made equal. It also correlates with different similar studies. ${ }^{6-8}$
30
BF 10
BF20
BF30

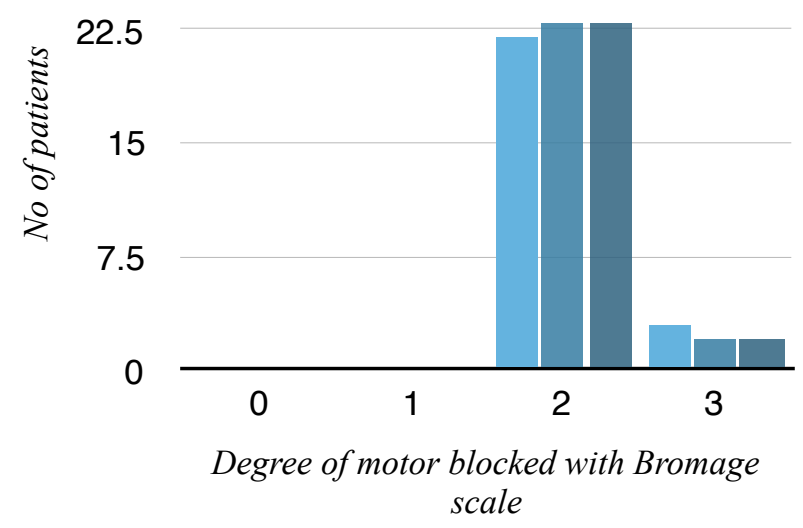

Figure 2. Quality of motor block amongst the various study groups 
Pedersen et al. ${ }^{8}$ using a Bupivacaine dose of 7.5-10 $\mathrm{mg}$ reported a $70 \%$ incidence of visceral pain during peritoneal traction. In our study, all the patients had adequate to excellent intraoperative analgesia. None of the patient required intraoperative supplemental analgesia and although quality of analgesia significantly improved from 10 to $20 \mu \mathrm{g}$, it did not improve significantly from 20 to $30 \mu \mathrm{g}(\mathrm{p}=0.189)$. In the study done by Belzarena et $a 1 .^{6}$, quality of intraoperative analgesia was better in Fentanyl groups than in Bupivacaine only group, however there was no difference in analgesia as the dose of Fentanyl increased from $0.25 \mu \mathrm{g} / \mathrm{kg}$ to $0.75 \mu \mathrm{g} / \mathrm{kg}$. Similar findings were observed in other studies done by by Jain et al. ${ }^{9}$ and Seewal et al. ${ }^{10}$ The dose of Fentanyl recommended in these two studies for excellent intraoperative analgesia was $10 \mu \mathrm{g}$ which was lesser than $20 \mu \mathrm{g}$ used in our study. This may be because of the low dose of Bupivacaine that we used.

Degree of motor block was achieved as Bromage 2 in $80 \%$ to $90 \%$ of the cases in our study and the results among three groups was not statistically significant. Degree of motor block did not increase with the increasing dose of Fentanyl. Other studies also showed that the synergism of spinal local anesthetics and fentanyl was characterized by enhanced somatic analgesia without effect on the degree or level of the local anesthetic-induced sympathetic or motor blockade. ${ }^{11,12}$ Choi, Hunt and Goel et al. concluded that motor recovery time did not change with additional Fentanyl combined to spinal Bupivacaine. $7,13,14$

In our study, duration of effective analgesia, defined as time to demand for first rescue analgesic, was $173.64 \pm 41$ minutes, $216.80 \pm 32$ minutes and $273.16 \pm 35$ minutes in Group BF10, BF20 and BF30 respectively. Although the duration of effective analgesia increased on increasing the dose of Fentanyl from 10 to $30 \mu \mathrm{g}$, visual analogue scale at the time of first rescue analgesic was similar in all the three groups. This finding was in consistent with the other studies. ${ }^{6,7,15-17}$ This suggests that Fentanyl increases the duration of postoperative analgesia reducing the need for early use of analgesic.

In our study, neonatal condition was similar in all groups with APGAR scores almost always above 7 at $1 \mathrm{~min}$ and always above 7 at $5 \mathrm{~min}$. The dose of intrathecal Fentanyl upto $30 \mu \mathrm{g}$ didn't seem to influence the clinical condition of neonate. Seewal et al. ${ }^{10}$, Belzarena et al. ${ }^{6}$ and Hunt et al. ${ }^{7}$ in their study showed that the APGAR score of neonates did not decrease as the dose of intrathecal Fentanyl was increased up to $40 \mu \mathrm{g}, 50 \mu \mathrm{g}$ and $0.75 \mu \mathrm{g} / \mathrm{kg}$ respectively.

The commonest side effects of fentanyl are nausea, vomiting, pruritus, and respiratory depression. ${ }^{18}$ In our study pruritus was seen in four patients from BF30 to whom intravenous Ondansetrone $(0.1 \mathrm{mg} /$ $\mathrm{kg}$ ) was given. One patient in BF20 had pruritus which was not so severe and none in BF10 had pruritus. The levels of sedation score were similar in all the three groups. None of the patient in our study developed respiratory depression which was measured by pulse oximetry. Nausea and vomiting is also a known complication of intrathecal opioids and have been reported as major side effects in some studies.6,7,9,20 In our study, none of the patients complained of nausea and vomiting during intraoperative and postoperative period which may be because of intrathecal injection of Fentanyl as an adjuvant to hyperbaric Bupivacaine that attenuates the incidence of nausea and vomiting as reported in few studies. ${ }^{18,19}$ We could not study the propensity of intrathecal Fentanyl to cause urinary retention because all of our patients were routinely catheterized as part of preparation for surgery.

\section{CONCLUSIONS}

Intrathecal Fentanyl, added as an adjuvant at doses of 10,20 and $30 \mu \mathrm{g}$ with low dose of Bupivacaine 
provided good intraoperative and postoperative postoperative analgesia lasts longer but at the cost of quality of spinal anesthesia with $20 \mu \mathrm{g}$ showing the increased adverse effects like pruritus.

excellent result. As the dose of Fentanyl increases,

To cite this article: Thapa $\mathrm{P}$, Shrestha AB, Rayamajhi M. Anesthetic Effects of Varying Doses of Fentanyl Combined with Spinal Bupivacaine in Caesarian Delivery. MJSBH. 2018;17(1):3-10.

Conflict of Interest: None declared

\section{REFERENCES}

1. Betrán AP, Ye J, Moller A-B, Zhang J, Gülmezoglu AM, Torloni MR. The Increasing Trend in Caesarean Section Rates: Global, Regional and National Estimates: 1990-2014. Zeeb H, ed. PLoS ONE. 2016;11(2):e0148343.

DOI:10.1371/journal.pone.0148343.

2. Choi DH, Ahn HJ, Kim MH. Bupivacaine-sparing effect of Fentanyl in spinal anesthesia for cesarean delivery. Reg Anesth Pain Med. 2000 May-Jun;25(3):240-5.

DOI: //doi.org/10.1097/00115550-200005000-00006

3. De Simone CA, Leighton BL, Norris MC. Spinal anesthesia for cesarean delivery. A comparison of two doses of hyperbaric bupivacaine. Reg Anesth. 1995 Mar-Apr;20(2):90-4.

PMID 7605770

4. De Kock M, Gautier P, Fanard L, Hody JL, Lavand'homme P. Intrathecal ropivacaine and clonidine for ambulatory knee arthroscopy: a dose-response study. Anesthesiology. 2001;94(4):574-8.

DOI: //doi.org/10.1097/00000542-200104000-00008

5. Kaya T, Buyukkocak U, Basar H, Sagsoz N. Comparison of epidural ropivacaine $0.2 \%$ and ropivacaine $0.2 \%$ in combination with sufentanil $0.75 \mathrm{microg} / \mathrm{ml}$ for postcaesarean analgesia. Agri. 2008 Oct;20(4): $30-7$.

6. Belzarena SD. Clinical effects of intrathecally administered Fentanyl in patients undergoing cesarean section. Anesth Analg. 1992 May;74(5):653-7.

DOI:https://doi.org/10.1213/00000539-199205000-00006

7. Hunt CO, Naulty JS, Bader AM, Hauch MA, Vartikar JV, Datta S, et al. Perioperative analgesia with subarachnoid Fentanyl-Bupivacainefor cesarean delivery. Anesthesiology. 1989 Oct;71(4):535-40.

DOI:https://doi.org/10.1097/00000542-198910000-00009 
8. Pedersen H, Santos AC, Steinberg ES, Schapiro HM, Harmon TW, Finster M. Incidence of visceral pain during cesarean section: the effect of varying doses of spinal bupivacaine. Anesthesia \& Analgesia. 1989;69(1):46-9.

DOI:https://doi.org/10.1213/00000539-198907000-00009

9. Jain K, Grover VK, Mahajan R, Batra YK. Effect of varying doses of Fentanyl with low dose spinal Bupivacaine for caesarean delivery in patients with pregnancy-induced hypertension. Int J Obs Anesth. 2004; 13:215-20.

DOI:https://doi.org/10.1016/j.ijoa.2004.04.006

10. Seewal R, Shende D, Kashyap L, Mohan V. Effect of addition of various doses of Fentanyl intrathecally to $0.5 \%$ hyperbaric Bupivacaineon perioperative analgesia and subarachnoid-block characteristics in lower abdominal surgery: a dose-response study. Reg Anesth Pain Med. 2007 Jan-Feb;32(1):20-6.

DOI: https://doi.org/10.1016/j.rapm.2006.09.007

11. Ben-David B, Solomon E, Levin H, Admoni H, Goldik Z. Intrathecal Fentanyl with small-dose dilute bupivacaine: better anesthesia without prolonging recovery. Anesth Analg. 1997 Sep;85(3):560-5.

DOI: https://doi.org/10.1097/00000539-199709000-00014

12. Dhumal PR, Kolhe EP, Gunjal VB, Kurhekar VA. Synergistic effect of intrathecal Fentanyl and Bupivacaine combination for cesarean section. Int J Pharm Biomed Res. 2013;4(1):50-6.

13. Zohar E, Noga Y, Rislick U, Leibovitch I, Fredman B. Intrathecal anesthesia for elderly patients undergoing short transurethral procedures: a dose-finding study. Anesth Analg. 2007 Mar;104(3):552-4. DOI: https://doi.org/10.1213/01.ane.0000255329.55037.cd

14. Goel S, Bhardwaj N, Grover VK. Intrathecal Fentanyl added to intrathecal Bupivacainefor day case surgery: a randomized study. Eur J Anaesthesiol. 2003 Apr;20(4):294-7.

DOI: https://doi.org/10.1097/00003643-200304000-00004

15. Chu CC, Shu SS, Lin SM, Chu NW, Leu YK, Tsai SK, et al. The effect of intrathecal Bupivacainewith combined Fentanyl in cesarean section. Acta Anaesthesiol Sin. 1995 Sep;33(3):149-54.

PMID: 7493145

16. Wong CA, Scavone BM, Slavenas JP, Vidovich MI, Peaceman AM, Ganchiff JN, et al. Efficacy and side effect profile of varying doses of intrathecal Fentanyl added to Bupivacainefor labor analgesia. Int $\mathbf{J}$ Obstet Anesth. 2004 Jan;13(1):19-24.

DOI:https://doi.org/10.1016/s0959-289x(03)00106-7

17. Harsoor SS, Vikram MS. Spinal anaesthesia with low dose Bupivacaine with Fentanyl for cesarean section. SAARC J Anaesth. 2008;1(2):142-5.

18. Manullang TR, Viscomi CM, Pace NL. Intrathecal Fentanyl is superior to intravenous ondansetron for the prevention of perioperative nausea during cesarean delivery with spinal anesthesia. Anesth Analg. 2000 May;90(5):1162-6.

DOI: https://doi.org/10.1097/00000539-200005000-00030 
19. Siddik-Sayyid SM, Aouad MT, Jalbout MI, Zalaket MI, Berzina CE, Baraka AS. Intrathecal versus intravenous Fentanyl for supplementation of subarachnoid block during cesarean delivery. Anesth Analg. 2002 Jul;95(1):209-13.

DOI: https://doi.org/10.1097/00000539-200207000-00037

20. Marucci M, Diele C, Bruno F, Fiore T. Subarachnoid anaesthesia in caesarean delivery: effects on alertness. Minerva anestesiologica. 2003;69(11):809-19. 